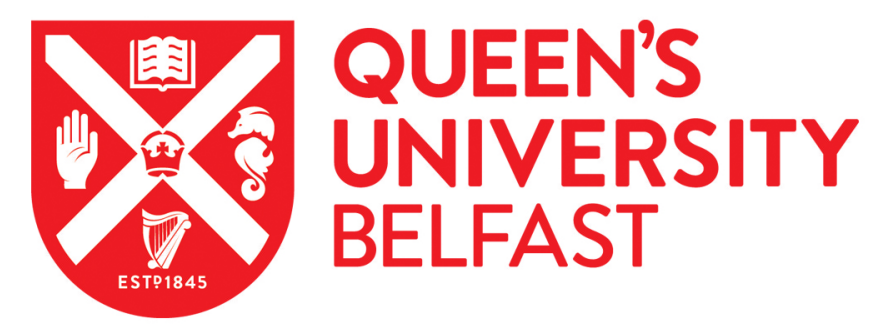

\title{
Are pesticides risk decreasing? The relevance of pesticide indicator choice in empirical analysis
}

Moehring, N., Bozzola, M., Hirsch, S., \& Finger, R. (2020). Are pesticides risk decreasing? The relevance of pesticide indicator choice in empirical analysis. Agricultural Economics , 51(3), 429-444.

https://doi.org/10.1111/agec.12563

Published in:

Agricultural Economics

Document Version:

Peer reviewed version

Queen's University Belfast - Research Portal:

Link to publication record in Queen's University Belfast Research Portal

Publisher rights

Copyright 2020 Wiley. This work is made available online in accordance with the publisher's policies. Please refer to any applicable terms of use of the publisher.

\section{General rights}

Copyright for the publications made accessible via the Queen's University Belfast Research Portal is retained by the author(s) and / or other copyright owners and it is a condition of accessing these publications that users recognise and abide by the legal requirements associated with these rights.

Take down policy

The Research Portal is Queen's institutional repository that provides access to Queen's research output. Every effort has been made to ensure that content in the Research Portal does not infringe any person's rights, or applicable UK laws. If you discover content in the Research Portal that you believe breaches copyright or violates any law, please contact openaccess@qub.ac.uk. 


\section{Are pesticides risk decreasing? The relevance of}

\section{pesticide indicator choice in empirical analysis}

Authors: Niklas Möhring ${ }^{1 *}$, Martina Bozzola ${ }^{2,3}$, Stefan Hirsch ${ }^{4}$, Robert Finger ${ }^{1}$

${ }^{1}$ Agricultural Economics and Policy Group, ETH Zurich, Sonneggstrasse 33, 8092 Zurich, CH.

${ }^{2}$ Institute for Global Food Security, School of Biological Sciences, Queen's University Belfast, Belfast, UK

${ }^{3}$ Institute of Natural Resource Sciences. The ZHAW Zürich University of Applied Sciences, Wädenswil CH

${ }^{4}$ Technical University of Munich, School of Management, Alte Akademie 12, 85354 Freising, Germany

*Corresponding author: nmoehring@ethz.ch, +41 446320767. 


\begin{abstract}
The reduction of adverse health and environmental effects from pesticide use is currently a top priority on the agricultural policy agenda. Efficient pesticide policies must take into account farmers' application behavior, especially effects of pesticide use on economic risk. However, previous results regarding the direction of risk effects of pesticides are ambiguous. We show that the ambiguity in earlier studies could be due to the pesticide indicator selected. Indicators which fail to account for the heterogeneous properties of pesticides may be inapt for interpreting farmers' pesticide use decisions. Our analysis, based on a rich panel dataset of Swiss wheat producers with highly detailed information on pesticide use, considers different pesticide indicators and multiple sources of uncertainty. Our key finding is that indicator choice affects the magnitude and sign of estimated risk effects. Estimates of pesticide productivity and risk effects are significantly higher for fungicides, and even reversed for herbicides when we measure pesticide use in simple quantity units (kilogram per hectare) - compared to the quality and intensity corrected Load Index. This means for example, that farmers will ceteris paribus use lower quantities of herbicides, but will increase the overall toxicity of the products applied with increasing risk aversion. We discuss implications of our findings for the design of pesticide policies and agricultural risk management instruments.
\end{abstract}

Keywords: Pesticides, pesticide policies, risk management, pesticide indicators, damage abatement

\title{
JEL classifications: D24, Q12, Q15, Q18
}




\section{Introduction}

Pesticides are an important input for agricultural production, however their application can have adverse effects on human health and the environment (Pimentel and Burgess, 2014; Larsen et al., 2017; Lai, 2017). The reduction of adverse effects from pesticide use is on the agricultural policy agenda in the EU, the US, China and several other countries (Osteen and Fernandez-Cornejo, 2013; Lefebvre et al., 2015; Lai, 2017). In the EU, for instance, the introduction of national action plans (NAPs) is mandatory for all EU member states since 2012. Pesticide policies in the different NAPs range from subsidies for upgrading equipment, schooling of farmers and awareness enhancement to the introduction of pesticide taxes (Böcker and Finger, 2016).

Risk effects of pesticides, as well as farmers' risk perception and preferences ${ }^{1}$ have been shown to play an important role in farmers' pesticide use behaviour (Skevas et al., 2013a; Trujillo-Barrera et al., 2016; Gaba et al., 2016). This is because potential pest pressure or damage arising from different pests, are highly uncertain at the time of pesticide application (Pannell, 1991; Horowitz and Lichtenberg, 1994). Therefore, efficient pesticide policies need to consider risk effects of pesticides. Empirical evidence on the direction of these risk effects though is inconclusive: Existing studies have detected risk increasing, risk decreasing and no risk effects of pesticides (see online appendix, Table A1 for a literature overview). Ambiguous findings may be due to the varied set of indicators employed for the measurement of pesticide use in literature.

This article provides a conceptual and empirical framework to revisit the risk effects of pesticides. More specifically, we examine the role of pesticide indicator choice in the empirical analysis of risk effects of pesticides. We choose an empirical strategy based on the framework of Saha et al. (1997), which accounts for the fact that farmers make pesticide use decisions under uncertainty regarding both crop growth conditions and pest pressure. In this framework, we perform an analysis of the

\footnotetext{
${ }^{1}$ Note that throughout this article, "risks" refer to economic risks if not specified otherwise (e.g. environmental and health risks). Farmers' risk preferences are observed to range largely, while farmers on average tend to be risk averse (e.g. Iyer et al., 2019).
} 
effects of herbicide and fungicide use on the mean and variance of revenues, for the case of Swiss wheat production. The highly detailed dataset allows to differentiate effects per pesticide type and to compare results for two different indicators of pesticide use, i.e. physical quantities $(\mathrm{kg} / \mathrm{ha})$ of pesticides as well as the dosage and quality adjusted Load Index (LI).

Indicators of pesticide use utilized in empirical analysis on risk effects of pesticides have been based on i) physical quantities of active ingredients (e.g. Di Falco and Chavas, 2006), ii) the number of applications (e.g. Regev et al., 1997) or iii) monetary values of pesticide expenditures (e.g. Koundouri et al., 2009; Gardebroek et al., 2010). However, the use of different measures does not necessarily lead to similar conclusions about farmers' pesticide use intensity. Recent studies show that pesticides differ widely with respect to standard application doses, costs per unit of planted area and important qualitative dimensions, such as toxicity (Kniss, 2017; Möhring et al., 2019). Indicators, which fail to account for the heterogeneous properties of pesticides, may thus be inapt to interpret farmers' pesticide use decisions and to guide the design of new pesticides policies. We investigate the importance of indicator choice for the estimation of risk effects by comparing a quantitative-only indicator $(\mathrm{kg} / \mathrm{ha})$ to the LI indicator in our analysis. The LI indicator accounts for differences in dosage, as well as potential environmental and health impacts of pesticides on a product level (Kudsk et al., 2018) ${ }^{2}$.

Our key finding is that indicator choice affects the magnitude and sign of estimated risk effects. For example, with increasing risk aversion, farmers will ceteris paribus use lower quantities of herbicides, but will increase the overall toxicity of the products applied. These results have important implications for pesticide policies and the design of agricultural risk management instruments.

The article is structured as follows. Section 2 presents an overview of the existing literature. Section 3 outlines the conceptual and econometric framework, followed by a description of the data in Section

\footnotetext{
${ }^{2}$ Note that we compare the effects of indicator choice on the estimation of pesticide productivity and risk effects in our analysis, but do not explicitly analyze environmental and health impacts of pesticide use (e.g. Skevas et al., 2013b).
} 
4 and a discussion of empirical results in Section 5. Section 6 completes the article with conclusions and recommendations for the design and implementation of pesticide policies.

\section{Background}

Our literature review on the risk effects of pesticide use (Table A1 in the online appendix) reveals ambiguous findings, with studies indicating increasing, decreasing or no effects of pesticides on risk. Three key observations from this overview are important for our analysis: firstly, the studies differ widely across crops and regions analyzed. Secondly, the indicator applied to measure pesticide use varies substantially across studies (e.g. physical units, number of applications or monetary units). Thirdly, to our knowledge, no study considers the heterogeneity of pesticides with regard to qualitative differences (i.e. toxicity) ${ }^{3}$.

Most of the reviewed studies do not interpret results in the light of the pesticide use indicators employed even though pesticides are very heterogeneous with regard to effective quantities needed for treatment, as well as qualitative aspects, i.e. properties of the inherent active ingredients and their efficacy. Möhring et al. (2019) find that quantity-based pesticide indicators fail to identify important qualitative characteristics of pesticides, especially for those applications, which show the highest values of the LI pesticide risk indicator. Kniss (2017) emphasizes that failure to correct for quantitative and qualitative differences in pesticides leads to flawed results in a study on long-term (average) herbicide use trends in US agriculture.

The insights gained from these studies show that the omission of important qualitative pesticide properties could lead to serious variations in the estimation of pesticide productivity and risk effects. For example, Skevas et al. (2013b) find that pesticides with higher toxicity have long-term negative effects on biodiversity and production levels. Zhengfei et al. (2005) emphasize that pesticides can have adverse agronomic effects, such as phyto-toxicity, adaption (increasing decomposition of

\footnotetext{
${ }^{3}$ Antle $(1988,2010)$ mentions the need to account for different pesticide properties, although he does not explicitly consider them. Instead, he uses hedonic pricing to adjust for quality differences.
} 
pesticides by micro-organisms), the development of secondary pests and changes in output quality. Indicator choice could also affect the estimation of the risk effects of pesticides, when important pesticide properties are not considered. For example, in the prominent case of glyphosate use in the US, weed resistance might pose a high risk to production and thus induce the use of more toxic herbicides (Teixeira et al., 2007; Yuan et al., 2007; Perry et al., 2016; Kniss, 2017; Swinton and Van Deynze, 2017). At present, there is no indicator of pesticide efficacy available for the economic analysis of pesticide use decisions. Therefore, we assume that there is a close relationship between the potential adverse effects of a given pesticide on the environment and human health and its efficacy (that is, we assume that farmers maximize efficacy of the pesticides they use, while minimizing potential adverse effects).

\section{Methodology}

\subsection{Conceptual framework}

Traditionally, pesticides are seen as a risk decreasing input, so that the optimal level of pesticide use increases with the level of risk aversion (Feder, 1979). In contrast, Horowitz and Lichtenberg (1994) show that pesticides can be either risk increasing or decreasing inputs depending on the uncertainty associated with crop growth and pest development. We adapt their model to develop a conceptual framework for our analysis. Based on this framework, we then discuss how we can investigate the extent to which a focus on specific pesticide types (e.g. herbicides), or the use of different pesticide indicators can influence the estimation of risk effects of pesticides.

In our analysis, we define production risk as the variability in crop revenues. We choose revenues as the outcome variable as it captures both changes in crop quantity and quality. This is important, as pests affect the variability of both the quantity and quality of crops, e.g. through plant diseases like Fusarium and associated deoxynivalenol contents in the cultivation of winter wheat. 
We assume that crop output $(y)$ is a function of a vector of inputs (x) and a vector of random factors (E). We then define the production function ${ }^{4}$ as

$$
y=f(\mathbf{x}, \boldsymbol{\varepsilon})
$$

Further, we assume that vector $\boldsymbol{\varepsilon}$ contains two elements as major sources of uncertainty for crop production and is distributed as

$$
G(\varepsilon)=f(\phi, \theta)
$$

where, $\phi$ represents (an index of) stochastic factors influencing crop growth conditions, such as the amount of rainfall over a given time period. Assuming that $\phi$ is ordered from bad states of nature to good states of nature, then $f(\mathbf{x}, \phi)_{\phi}>0$, i.e. output increases with better crop growth conditions. Moreover, $\theta$ represents (an index of) stochastic factors influencing pest development, e.g. variability in pest infestation levels, damage associated with infestation levels or pesticide effectiveness. Assuming also that $\theta$ is ordered from bad states of nature to good states of nature (e.g. from high to low infestation levels), then $f(\mathbf{x}, \theta)_{\theta}>0$. Lichtenberg and Zilberman (1986) argue that in contrast to productive inputs such as land, seeds or water, pesticide use does not raise the upper threshold for potential output, but rather decreases the gap between potential and realized output. Accordingly, we treat pesticides as damage abating inputs:

$$
f(\mathbf{x}, \mathbf{z}, \mathbf{s}, \phi, \theta)=h(\mathbf{x}, \mathbf{s}, \phi) *(1-d(\mathbf{z}, \mathbf{s}, \theta)) .
$$

where $\mathbf{z}$ is a vector of damage abating inputs, $h(\mathbf{x}, \mathbf{S}, \phi)$ is potential output and $d(\mathbf{z}, \mathbf{s}, \theta)$ is the damage function (i.e. the proportion of crops damaged by pests). In line with Saha et al. (1997), we not only differentiate between purely productive inputs $(\mathbf{x})$ and purely damage abating inputs (z), but also consider a third group of "interactive" inputs, which are both productive and damage abating, denoted by $\mathbf{s}$.

\footnotetext{
${ }^{4}$ Note that the focus here lies on crop yield as a stochastic variable determined by pest pressure. Horrowitz and Lichtenberg (1994) show that similar reasoning also applies when the dominant sources of uncertainty are market conditions or product quality.
} 
We can use the model in Eq. 3 to understand the effect pesticides have on production risk in different scenarios with regard to stochasticity of crop growth and pest development conditions. Horowitz and Lichtenberg (1994) show that pesticide use reduces production risk in the case of deterministic crop growth conditions but significant stochastic, pest pressure (e.g. production under nets with irrigation). Further, they show that pesticides are risk increasing if crop growth conditions are stochastic but pest pressure is stable and deterministic. Deterministic pest pressure occurs in particular if farmers can easily predict weed pressure due to spill over of weed infestation in previous periods. At the same time, fluctuating weather conditions might have a strong influence on attainable output levels. This reasoning also applies for settings where the dominant sources of uncertainty are market conditions (e.g. production in greenhouses) or product quality (e.g. fruit production).

It is realistic to assume that both crop growth conditions and pest pressure are stochastic in most agricultural systems, including our case study on Swiss wheat production (with rain-fed production and mostly stochastic pest pressure). Horowitz and Lichtenberg (1994) find that the risk effect of pesticide use in this scenario depends on the correlation between the two stochastic factors and their marginal contributions to crop growth/pest development. We expect that better crop growth conditions and better conditions for pest development are positively correlated for the majority of pests in Swiss wheat production. For example, warm and wet growing conditions stimulate crop growth but also cause higher weed and fungi pressure - the most relevant pests in Swiss winter wheat production. In contrast, there is some (though mixed) evidence that drought conditions, which lead to lower crop yields, actually favor crop damage from insects (Dorschner et al., 1986; Maxmen, 2013). To summarize, risk effects of pesticides are expected to depend on i) the variability of pest pressure and the type of pest, ii) the variability of growing conditions determining the level of expected yields, and iii) output market conditions.

This theoretical model provides reasoning why different types of pesticides, such as herbicides, fungicides or insecticides can have different or even opposing effects on production risks. Moreover, 
the identified effects of pesticides on crop yield distributions depend on the chosen pesticide indicator. Based on the findings in Kniss (2017) and Möhring et al. (2019), a simple, quantitative indicator would omit important (qualitative) dimensions of the pesticides used and therefore fail to reflect an important factor in the farmers' decision-making process ${ }^{5}$. For example, in cases of high production risks (e.g. high pest pressure, resistant pests), quantitative indicators might suggest a reduction of pesticide use when in reality farmers applied lower quantities of a more efficient pesticide - and vice versa. This implies that the estimation of risk effects may depend crucially on the choice of the pesticide indicator.

In line with Saha et al. (1997) and Zhengfei et al. (2005), we build upon Eq. 3 and test the hypothesis from the conceptual framework in the following "testing framework":

$f(\mathbf{x}, \mathbf{z}, \mathbf{s}, \mathbf{x z}, \phi, \theta)=h\left(\mathbf{x}, \boldsymbol{s}, \mathbf{z}_{\boldsymbol{p f}}, \boldsymbol{x} \mathbf{z}, \phi\right) *\left(1-d\left(\mathbf{s}, \mathbf{z}_{\text {daf }}, \theta\right)\right)$

where $\mathbf{x}, \mathbf{z}, \mathbf{s}, \phi$ and $\theta$ denote vectors of inputs and error components as described above, $\mathbf{x z}$ includes all interactions of the variables in $\mathbf{x}$ and $\mathbf{z}$, and $\mathbf{z}_{\boldsymbol{p f}}$ and $\mathbf{z}_{\boldsymbol{d a f}}$ denote the same set of damage abating inputs $\mathbf{z}$, in the production and damage abatement function, respectively.

Firstly, we use separability tests in this framework to assign inputs to either $\mathbf{x}, \mathbf{z}$ or $\mathbf{S}$. The idea behind separability tests is that inputs are correctly classified when there are no interactions between purely productive (x) and purely damage abating (z) inputs since in this case all inputs which are both productive and damage abating are included in $\mathbf{s}$. The fulfilment of this condition can be tested in the above framework by assessing if the coefficients of the interaction terms $\mathbf{x z}$ between the variables in $\mathbf{x}$ and $\mathbf{z}$ differ significantly from zero. In accordance with Saha et al. (1997) and Zhengfei et al. (2006) the separability tests were performed three times (i.e. in three different testing frameworks) to increase robustness of the testing procedure (see online appendix B1 for a detailed description).

Secondly, we perform asymmetry tests to determine if the use of a damage abatement

\footnotetext{
${ }^{5}$ Important drivers of the choice of pesticides, apart from their inherent properties, might also be the efficiency of products per monetary unit or application behavior of farmers (Perry et al., 2019).
} 
specification of the output function is preferable over the use of a "classical" specification, which assumes a symmetric treatment of all inputs. More specifically, if the coefficients of $\mathbf{z}_{\boldsymbol{p} \boldsymbol{f}}$ in function $h($.$) do not differ significantly from zero, while those of \mathbf{z}_{\text {daf }}$ in function $d($.$) differ significantly$ from zero we can confirm the choice of a damage abatement specification (Zhengfei et al. 2006, see online appendix B1 for a detailed description).

Thirdly, we can test the veracity of our assumption of a positive covariance between crop growth conditions and pest pressure $(\phi$ and $\theta$ ). Due to the assumed order of the states of nature, the hypothesis of a positive relationship between crop growth and pest development relates to a negative correlation of $\phi$ and $\theta$ in the model.

Fourthly and most importantly, the framework allows us to test for changes in the sign and magnitude of productivity and risk effects of pesticides with regard to various pesticide types and the choice of different pesticide indicators. To test for differences between indicators, we estimate pesticide productivity and risk effects using the quantitative-only "Pesticide Quantity" (PQ) indicator and the "Load Index" (LI) indicator and compare results. The first indicator links this study to numerous earlier studies, which commonly used "quantitative-only" indicators (see Table A1 in the online appendix). The second indicator additionally accounts for qualitative differences of pesticides and is therefore especially relevant in the light of current pesticide policies and the above-formulated conceptual framework.

\subsection{Econometric framework}

In line with the conceptual model, we employ an econometric framework based on a production function with two error components and damage mitigation. To this end, we combine the "two error components framework" developed by Saha et al. (1997) with a specification of the damage 
mitigation function proposed by Zhengfei et al., (2005) $)^{6}$ Hence, we specify the output function as follows:

$$
Y=F\left(\mathbf{x}, \mathbf{s}, \mathbf{x}_{\mathbf{c}}, \beta\right) * \exp (\phi) * \exp (-A(\mathbf{z}, \mathbf{s}, \alpha) * \theta)
$$

with $\phi \sim N(0,1), \theta \sim N(\mu, 1)$ and $\operatorname{cov}(\phi, \theta) \equiv \rho$.

where $Y$ denotes output, $F\left(\mathbf{x}, \mathbf{s}, \mathbf{x}_{\mathbf{c}}, \beta\right) * \exp (\phi)$ denotes the production function, $\exp (-A(\mathbf{z}, \mathbf{s}, \alpha) *$ $\theta$ ) denotes the damage abatement function and $\sim N($.$) denotes a normal distribution. The two error$ components $\phi$ and $\theta$ relate directly to the two sources of uncertainty described in our conceptual framework. The empirical model explicitly accounts for possible correlation $(\rho)$ between these two error components. The estimated correlation parameter allows us to test both the validity of our model choice compared to simpler model specifications and our expectations regarding the correlation of crop growth and pest development conditions.

We denote vectors of inputs, including fertilizer (i.e. kg of nitrogen), labor, machinery, herbicides, fungicides and mechanical pest $\operatorname{control}^{7}$, by $\mathbf{x}, \mathbf{z}$ and $\mathbf{s}$. The latter extends the set of potential damage abatement inputs originally considered by Saha et al. (1997). Furthermore, we treat mechanical pest control and chemical pest control separately to capture possible substitutions and interactions ${ }^{8}$. We allocate different inputs to either category based on separability tests and support the choice of a damage abatement formulation of the production function, compared to a more general specification, with tests on asymmetry of inputs (see above). As a result, labor and machinery were assigned to the set of purely productive inputs (x), pesticides and mechanical pest control to the set of damage abating inputs $(\mathbf{z})$ and fertilizer to interactive inputs (s). Furthermore, we confirm the choice of a damage abatement specification of the output function (Equation 5) and a specification, which accounts for

\footnotetext{
${ }^{6}$ See for example Shankar et al. (2008) and Kan et al. (2014) for other applications of the two-error components framework. The damage mitigation approach is based on the seminal work of Lichtenberg and Zilberman (1986). Similar applications of production functions considering damage abatement can be found in Saha et al., (1997); Zhengfei et al., (2006) or Shankar et al., (2008).

${ }^{7}$ Note that mechanical pest control mainly includes mechanical weed control, but also involves a few cases of mechanical disease control.

${ }^{8}$ Charles et al. (2011) and Böcker et al. (2019) show that interactions and substitutions between mechanical and chemical pest management practices are important in Swiss winter wheat production.
} 
correlation of the error components. See the results section for a discussion of test results. The vector of variables used to control for farm-level heterogeneity (see below for a discussion on estimation issues with regard to potential unobserved heterogeneity) includes variables for regional, political and cultural differences, different topographic zones, year effects and farm specialization and is denoted by $\mathbf{x}_{\mathbf{c}}$.

Based on Equation 5 and following Saha et al. (1997), output is then assumed to follow a lognormal distribution, so that

$$
\ln Y \sim N[\ln F(.)-\mu * A(.), B(.)]
$$

with $B(.) \equiv\left[1+(A(.))^{2}-2 * A(). * \rho\right]$.

The assumption of a lognormal distribution allows flexible estimation of the risk effects of inputs in the model (Saha et al., 1997; Shankar et al., 2008) ${ }^{9}$. It also allows us to compare estimates of marginal productivity and marginal risk effects separately for the two indicators. Distributional assumptions are approximately justified (see online appendix B2).

Different functional forms for the damage abatement function $A($.$) have been employed and$ discussed in the literature (see e.g. Saha et al., 1997; Zhengfei et al., 2005; Shankar et al., 2008). We have identified two crucial characteristics. Firstly, the choice of the functional form must ensure that damage abatement stays within the range of $[0,1]$. Secondly, this choice must allow for negative marginal products of the inputs in the damage abating function (Zhengfei et al., 2005) ${ }^{10}$. More specifically, the misuse or overuse of pesticides might reduce quantity and quality of crop yields and can exhibit negative marginal products. Thus, in line with Zhengfei et al. (2005), we use the following quadratic damage abatement function:

\footnotetext{
${ }^{9}$ Thus, this specification is more flexible than other approaches. For example, Lichtenberg and Zilberman (1986) made the implicit assumption of non-negative marginal productivity of damage abatement inputs.

${ }^{10}$ Cobourn et al. (2011) show that structural models of damage abatement reduce estimation bias compared to the damage abatement approach chosen here. However, the complexity of the analyzed bio-physical system and the lack of data on pest infestation make their approach infeasible in our case.
} 


$$
A(\mathbf{z}, \mathbf{s}, \boldsymbol{\alpha})=\left(\alpha_{0}+\alpha_{1} * \mathbf{s}+\alpha_{2} * \mathbf{z}\right)^{2}
$$

Where $\mathbf{s}, \mathbf{z}$ and $\boldsymbol{\alpha}$ denote the sets of inputs described above, as well as their respective coefficient vectors.

We use a Cobb-Douglas functional form for the production function (in line with previous works by Saha et al., 1997; Shankar et al., 2008; Kan et al., 2014) ${ }^{11}$ :

$$
F(\mathbf{x}, \mathbf{s}, \boldsymbol{\beta})=\prod_{k} x_{k}^{\beta_{x k}} \mathrm{~s}_{k}^{\boldsymbol{\beta}_{s k}} * \exp \left(\boldsymbol{\beta}_{c}^{\prime} \mathbf{x}_{\mathrm{c}}\right)
$$

Where $\prod$ denotes the product operator and $\mathrm{k}$ stands for the kth input of the sets of inputs $\mathbf{x}$ and $\mathbf{s}$ with the respective coefficients $\beta_{x k}$ and $\beta_{s k}$. Further, $\mathbf{x}_{c}$ and $\boldsymbol{\beta}_{c}$ denote the vectors of control variables and their respective coefficients.

Based on Equations 5, 7 and 8 we define our output function as follows:

$Y=\left(\prod_{k} x_{k}^{\boldsymbol{\beta}_{x k}} \mathbf{s}_{k}^{\boldsymbol{\beta}_{s k}} * \exp \left(\boldsymbol{\beta}_{c}^{\prime} \mathbf{x}_{\mathrm{c}}\right)\right) * \exp (\phi) * \exp \left(-\left(\left(\alpha_{0}+\alpha_{1} * \mathbf{s}+\alpha_{2} * \mathbf{z}\right)^{2}\right) * \theta\right)$.

The appropriate Log-likelihood-function for the estimation of the parameter vectors $\boldsymbol{\alpha}$ and $\boldsymbol{\beta}$ and the distribution parameters $\mu$ and $\rho$ is then (Saha et al., 1997)

$L L F(\boldsymbol{\alpha}, \boldsymbol{\beta}, \mu, \rho)=\frac{n}{2} \ln 2 \pi-0.5 \sum_{i t}\left(\ln B(.)_{i t}+\frac{\left[\ln Y_{i t}-\ln F(.)_{i t}+\mu A(.)_{i t}\right]^{2}}{1+\mu A(.)_{i t}^{2}-2 \rho A(.)_{i t}}\right)$.

Where $\rho$ depicts the correlation between the two error terms (see Equation 6), and the indices $i$ and $t$ denote single farms and years. We obtain parameter estimates with maximum likelihood estimation.

This framework allows an exact formulation of the output moments. From these, expressions for marginal effects of productive, damage abatement and interactive inputs on the mean and variance of output can be computed. Saha et al. (1997, p. 776-777, Equations 11a-14b) show the respective expressions for output moments and for marginal effects of inputs on mean and variance for each input type. As noted above, the here chosen model specification with two error terms (instead of the

\footnotetext{
${ }^{11}$ We also tested the more flexible trans-log functional form, but did not achieve convergence in the estimation of the non-linear equations.
} 
common damage abatement frameworks with one error component) has the advantage that we can derive separate marginal effects of inputs on mean and variance.

We estimate the above framework twice with two different indicators (PQ and LI) as a measure for pesticide use while the other variables remain unchanged. This paper focuses on the differences in marginal effects on the mean (i.e. productivity) and the variance (i.e. risk effects), i) across the two indicators and ii) across pesticide types. We test for differences with a z-test (Paternoster et al., 1998).

There is some concern that the estimations may be biased by endogeneity, due to potential measurement error and unobserved heterogeneity. In our case study, measurement error might introduce bias into the estimation if farmers report misleading pesticide use information. We address this concern by analyzing their compliance with pesticide regulations in the reported data. More specifically, we check if they report the application of pesticides in dosages, which exceed the legally permissible maximum. We find that farmers do not comply with regulations on maximum dosages in $5 \%$ of all herbicide applications and $3 \%$ of all fungicide applications in the data, indicating that they were unconcerned regarding anonymity and reported actual management decisions. Moreover, using the same dataset, Spycher et al. (2013) find that average pesticide application in the sample is in line with national pesticide sales statistics for Switzerland in $2009^{12}$.

Farm-level heterogeneity can introduce bias into the estimation if unobserved farm-level differences are correlated with input choices, i.e. through differences in technologies that farmers face (Carpentier and Weaver, 1996, 1997) or farm-specific reactions to productivity shocks (Levinsohn and Petrin, 2003, p. 317). While the latter is of no concern in our case study ${ }^{13}$, the former might still introduce

\footnotetext{
${ }^{12}$ Spycher et al. (2013) state that the dataset adequately covers pesticide use in field crops in particular (i.e. winter wheat) and for the most common pesticide types (herbicides and fungicides), and is representative of the country's farming sector. The authors find a slightly lower average pesticide use than in national sales statistics, as commonly reported for similar datasets.

${ }^{13}$ According to Olley and Pakes (1996) and Levinsohn and Petrin (2003), such shocks comprise productivity changes after policy shocks, a large number of market entries or exits of farms, or significant changes in farm size and investment in our case study. Our case study is characterized by minor changes in the number of farms and a small average farm size (see Table 1). Moreover, the Swiss farming sector is generally characterized by a low mobility of capital. Most importantly, during the years covered in the empirical analysis (i.e. 2009-2013) the sector was governed by a stable policy environment with regard to agricultural policy in general, and more specifically with regard to
} 
bias into the estimations. We use ANOVA to decompose overall variance of the output variable into variation across time and across farms to obtain an insight into the importance of heterogeneity across farms in the data (Carpentier and Weaver, 1996). The result shows that in our case study, only $17.5 \%$ of the variance is due to differences across farms (i.e. farm-level heterogeneity).

To address concerns regarding temporal variation, e.g. due to annual differences in weather, pest pressure or pesticide prices (Carpentier and Weaver, 1996) we include year dummy variables in our analysis. To address concerns about unobserved heterogeneity across farms (Carpentier and Weaver, 1997), we include farm-fixed effects in the above framework, but fail to achieve convergence of the non-linear maximum-likelihood functions. This is probably due to the highly unbalanced nature of our dataset, which leaves little farm-level variability to exploit for estimation purposes after demeaning (see Data section) ${ }^{14}$. Therefore, to investigate potential heterogeneity across farms we include a set of control variables and control for its most important sources. More specifically, we include a control variable to account for farmers' specialization and crop rotation practices, dummies for different topographic zones (valley and hilly regions vs. mountainous regions) and a dummy variable to control for political and cultural differences between French-speaking cantons (located in the west of Switzerland) and German-speaking cantons (in the midlands and east ${ }^{15}$. In addition, a comparison of estimation results of the commonly used PQ indicator with results of previous literature serves as a robustness check. If these estimates closely reflect productivity and risk effect estimates obtained previously by other studies (using a similar quantitative indicator), we can be confident that our estimation does not suffer from significant bias due to the remaining farm-level

pesticide policy. A more far-reaching change in Swiss agricultural policy with regard to environmental matters, took place in 2014 (Huber et al., 2017). In contrast to the European Union, a national action plan for pesticides was only introduced 2017.

${ }^{14}$ We test the inclusion of fixed effects on both the full dataset, as well as on a balanced subsample.

${ }^{15}$ Different pesticide reduction initiatives are launched on a cantonal level. In addition, the administration of agricultural education and extension services differ and are organized on a cantonal level. Furthermore, structural differences in farm characteristics and weather conditions might cause differences captured in an East-West distinction. Note that no farms in the southern (Italian speaking) part of Switzerland were part of the sample (Figure 1). 
heterogeneity ${ }^{16}$. Most importantly, even if some aspects of farm-level heterogeneity were not subject to control, the main interest of our analysis lies in the comparison of productivity and risk effects of pesticides across pesticide types and the pesticide indicators used. It follows that farm-level heterogeneity would only bias our results under the unlikely assumption that its effects differed along pesticide types and pesticide indicators.

\section{Data}

The main dataset used for the analysis is provided by the Swiss Central Evaluation of AgriEnvironmental Indicators (CE-AEI) and compiled with support of Agroscope (the Swiss Federal center of excellence for agricultural research; de Baan et al., 2015). The sample consists of an unbalanced panel of 95 Swiss winter wheat farmers from 2009 to 2013 with a total number of 268 observations. See Figure 1 for an overview of farm locations and Table A2 in the online appendix for a frequency count. Farmers report on their output quantity and quality, as well as input use. The data is unique in its detail as it includes daily information on i) the timing of each field management activity (e.g. tillage, seeding, mechanical plant protection) and ii) which specific inputs were used (e.g. names of pesticides used, fertilizers and machines) iii) in which quantities. We combine this dataset with yearly farm-level bookkeeping data from Agroscope (Mouron and Schmid, 2012), publicly available information on fate, toxicity and formulation of the applied pesticides (Lewis et al., 2016) and information on recommended standard application dosages of pesticides from the Swiss pesticide register (BLW, 2012).

\section{Figure 1. Location of sample farms in Switzerland}

We obtain yearly variables of farmers' input use from the raw data by calculating cost equivalents (in CHF: Swiss franc) for used machinery and working time for each reported management activity. Agroscope (2015) provides the detailed information on labor and machinery costs, needed for this

\footnotetext{
${ }^{16}$ We further account for the fact that we use repeated observations on a farm-level in the error structure of our estimations (using standard errors corrected for farm-level clustering) to infer properly on the significance of estimated parameters.
} 
calculation. We then convert reported fertilizer applications into nitrogen equivalents (in kilogram). The conversion of synthetic fertilizer is based on the product information; for organic fertilizer it is based on concentration and quality according to Agroscope (2009). We then aggregate labor (in $\mathrm{CHF}$ ), machinery (in $\mathrm{CHF}$ ) and fertilizer use (in $\mathrm{kg}$ ) per farmer and year to obtain the respective input variables. We derive yearly revenues from plot level yields and annual prices for six main quality categories of winter wheat (AGRIDEA, 2009-2013). Output and input variables are expressed on a per ha level, as suggested by Shankar et al. (2008). We deflate input and output prices to 2009 levels, using the consumer price index for Switzerland, excluding rental costs (BFS, 2016).

We use PQ and LI pesticide indicators to compute annual pesticide use variables, i.e. the sum of single applications in the cropping season. Firstly, we compute the amount of pesticides used in physical units (kg/ha), i.e. a purely quantitative indicator (PQ indicator). Secondly, the differences between the standard dosages and quality of pesticides are appraised and we compute the LI indicator (see Kudsk et al., 2018) ${ }^{17}$. The LI indicator standardizes the pesticide quantities applied according to their standard dosages and then performs a quality correction by weighting applications according to product-specific properties. Properties are assessed in three categories: the Human Health Load (based on hazard and precautionary statements) ${ }^{18}$, the Fate Load (based among others on half-life in soil and water and bio-concentration factors) and Eco-toxicity Load (based on long- and short-term toxicity for eight species). The LI indicator therefore provides a detailed depiction of pesticide properties in several dimensions. See online appendix B3 for a description of the computation procedure for both indicators. We calculate indicators separately for the two most relevant types of pesticides used in Swiss winter wheat production, i.e. herbicides (used on 95\% of plots in the sample)

\footnotetext{
${ }^{17}$ We adapt the computation scheme as described in Miljøministeriet (2012) and Kudsk et al. (2018). The framework of the indicator can be adapted easily to other countries using publicly available information (e.g. Möhring et al., 2019). It accounts for qualitative and quantitative differences on a product level and has been implemented in Denmark for a number of years (Kudsk et al., 2018), e.g. for pesticide taxation. The advantage being that the indicator has been tested and is in line with common European pesticide regulations.

${ }^{18}$ Liu and Huang (2013) find that farmers choose products in order to reach plant protection goals while minimizing risks in the health domain. Based on this reasoning, farmers would only use pesticides with a high health risk if they offer some efficiency benefits compared to other products. Thus, potential health impacts should be considered when analysing farmers' pesticide use decisions.
} 
and fungicides (used on $76 \%$ of plots in the sample). In Switzerland, herbicides are applied around planting time in late September to October and in the early spring of the subsequent year from March to April. Fungicides are applied later in the cropping season, from May to June. Möhring et al. (2019) detect a strong non-linear relationship between the purely quantitative PQ indicator and the qualityadjusted LI indicator for pesticide use in winter wheat production in Switzerland. Due to the nonlinear nature of the relationship between the indicators, effects of indicator choice on the estimation of risk effects cannot be predicted theoretically and therefore remain an empirical issue. Table 1 provides descriptions and summary statistics for input, output and control variables.

\section{Table 1. Summary statistics of variables}

The CE-AEI data collection scheme is based on farmers' voluntarily and remunerated participation. Farmers record data with a software (AGRO-TECH) which is also used to document observation of cross compliance obligations and is therefore integrated in daily farm management routines. Thus, there are no technical obstacles for farmers. Intermediaries collect the data to guarantee complete anonymity of participating farmers. The voluntary participation in the data collection process led us to address possible concerns regarding self-selection of farmers (see Section 3.1. for a discussion on concerns regarding self-reporting). Like Spycher et al. (2013), who consider pesticide use to be in line with national pesticide sales statistics, we find sample averages of total farm size, planted area of winter wheat and age to be close to population averages (see Table 2). In addition, we use the BACON algorithm to test the data for outliers with regard to revenues and inputs. This is a multivariate method that detects outliers, based on Mahalanobis distances (Billor et al., 2000). No significant outliers were identified ${ }^{19}$. We do not explicitly control for farm-specific, yearly changes in weather conditions, as farms are located in a relatively homogenous climatic region (Frei, 2014; Isotta et al., 2019). More specifically, farms in the sample are geographically distributed over the

\footnotetext{
${ }^{19}$ We use 1.5 percentiles of the chi-square distribution as the common threshold for outlier detection.
} 
Swiss Plateau (Figure 1), the main region for winter wheat production in Switzerland ${ }^{20}$. Dummy variables for years and regions capture potential weather shocks in our model.

\section{Table 2. Comparison of sample and population averages}

\section{$5 \quad$ Results}

Based on separability tests (see online appendix B1), we assign inputs to the three categories productive, damage abating and interactive. We identify work and machinery (excluding mechanical pest control) as purely productive inputs (x), herbicides, fungicides and mechanical pest control as purely damage abating inputs (z) and fertilizer as an interactive input (s). Results of the separability tests (see Table 3) confirm that input variables are assigned correctly, as we find no significant interactions between purely productive and purely damage abating inputs (see Section 3.1). This result holds in all of the three testing frameworks proposed by Saha et al. (1997) and Zhengfei et al. (2006). The assignment of fertilizer as an interactive input is further supported by literature. An abundance of evidence has been found in literature implying that fertilizer use not only leads to improved crop growth conditions, but also interacts with the development of pests and the efficacy of pesticides on pests, e.g. for weed growth, aphids and mildew (see e.g. Charles et al., 2011; Bürger et al., 2012).

Asymmetry test results show that coefficients of the damage abating inputs (z) differ from zero in the damage abating part $d($.$) but do not differ from zero in the production function part h($.$) of the output$ function. The results thus confirm our model choice with regard to a damage-abatement specification of the output function (see Section 3.1).

\section{Table 3. Test results of separability and asymmetry tests}

Based on the above specification of inputs, we estimate Equation (10) separately for Model 1 (using the PQ indicator) and Model 2 (using the LI indicator). Table A3 and Table A4 in the online appendix

\footnotetext{
${ }^{20}$ As a robustness check, we included seasonal temperature and rainfall variables on a municipality level, but do not find them to be significant (results available upon request). We therefore exclude them from the estimation.
} 
show estimation results. In line with our expectations and empirical evidence from previous studies (Saha et al., 1997; Shankar et al., 2008; Kan et al., 2014), we find a significant and positive coefficient estimate of $\rho$ in both models relating to a negative correlation of the two types of uncertainties in the conceptual model. The resulting estimate is very close to those in previous literature (see e.g. Saha et al., 1997). This indicates that uncertainties regarding crop growth conditions and pest development are highly correlated in Swiss winter wheat production. The coefficients of fertilizer in the damage abatement part are highly significant, empirically supporting the role of fertilizer in the damage abatement process. A comparison of the model fit of Models 1 and 2 reveals that the specification with the LI indicator slightly outperforms the specification with the PQ indicator (as it yields a higher log-likelihood value). We also note that, several coefficient estimates change and are even reversed when different pesticide indicators are used for estimations in the two models - see the following paragraphs on marginal effects for a detailed discussion.

Table 4 shows the marginal effects of damage abating and interactive inputs on expected revenue (evaluated at the sample mean) in the two models. Note that marginal effects are calculated for marginal changes in pesticide use as expressed in units of $\mathrm{kg}$ pesticides per ha (Model 1) and LI units per ha (Model 2). For example, in Model 1 farmers use an average of 1.59 PQ units (i.e. $\mathrm{kg} / \mathrm{ha}$ ) of herbicides, while they use 0.89 LI units in Model 2. Marginal effects can be interpreted as follows: an additional kilogram of fungicides per ha (Model 1) increases expected revenue by 29.33 CHF per ha, whereas an additional unit of the LI indicator of fungicides per ha increases revenue by $4.07 \mathrm{CHF}$ per ha ${ }^{21}$.

The marginal effects for herbicides are positive in Model 1 and negative in Model 2, while the marginal effects for fungicides are positive in both models. Differences between pesticide indicators

\footnotetext{
${ }^{21}$ The marginal product alone does not allow any conclusions on over- or underuse of pesticides -this would require a comparison with marginal costs (see Zhengfei et al., 2006). As the specification of pesticide expenditures in terms of the used indicators is not straightforward, this is beyond the scope of our article.
} 
(Model 1 and Model 2) are significant for both fungicides and herbicides (Table 5) ${ }^{22}$. Our findings show that indicator choice generally has an effect on the assessment of pesticide productivity and it is stronger for herbicides than for fungicides. Traditionally, cereal breeding in Switzerland has focused on making wheat varieties more tolerant to plant diseases (Walter et al., 2014). The tolerance of the dominant Swiss winter wheat varieties to plant diseases may indicate that fungicides are less important for pest management and explain the difference between herbicides and fungicides in our results. The results confirm our assumption that the LI indicator adds an important dimension to the assessment of pesticide productivity, compared to a purely quantitative measure like the PQ indicator. Pesticide quality seems to be relevant for the assessment of the (economic) efficiency of pesticides. The anticipated differences in pesticide productivity between pesticide types is likewise confirmed. The marginal effect of herbicides on revenues is lower than that of fungicides in both models (only significant in Model 2, see Table 5).

\section{Table 4. Marginal effects of damage abating and interactive inputs on expected revenues and variance}

Due to the interlinkages between mechanical and chemical pest control as well as fertilizer use and pesticide use (confirmed by the separability tests), marginal effects of mechanical pest control and fertilizer use also change with indicator choice. Marginal effects of mechanical pest control are positive in Model 1 and negative in Model 2 and coefficients are significantly different in the two models. Differences in estimates point in the same direction as for herbicide use (lower coefficient in Model 2), which is reasonable given their close linkage as potential substitutes in weed control. In both models estimates of the marginal effects of mechanical pest control (i.e. the average change in expected revenues, given an increase of mechanical pest control by $1 \mathrm{CHF} / \mathrm{ha}$ ) fall below $1 \mathrm{CHF}$ per ha. The findings of less than proportional or negative marginal effect on revenues may indicate an overuse of mechanical pest control practices. A typical example for the overuse of mechanical pest control is tillage, which might damage soil quality and therefore lead to lower yields and thus

\footnotetext{
${ }^{22}$ Note that due to the different units, disparities between Model 1 and Model 2 regarding the reported marginal effects for pesticide productivity, can only be interpreted unambiguously if sign changes occur (e.g. the case of herbicides). 
revenues. The coefficient of fertilizer is positive and significant in both Models and estimates do not differ significantly.

We will now look at marginal effects of the damage abating and interactive inputs on variance of wheat revenues, i.e. the risk effects. Table 4 (lower part) shows coefficient estimates (evaluated at the sample mean) for both Models. We express them as a percentage of the respective overall model variance, thus providing an impression of the relative magnitude of marginal effects.

\section{Table 5. Tests of differences between models and pesticide types}

The coefficient estimates can be interpreted as the relative effect of a one unit increase in pesticide use (measured in $\mathrm{kg} / \mathrm{ha}$ in Model 1 and in LI units/ha in Model 2) on the variance of revenues. We find significant, risk increasing effects of herbicides and fungicides in Model 1 (PQ indicator). This is in line with results of Gotsch and Regev (1996) and Regev et al. (1997), who investigated risk effects of fungicides in Swiss wheat production, using the number of applications as a simple, quantitative indicator for yearly pesticide use. However, note that these studies have accounted neither for simultaneous risk effects of herbicides and fungicides, nor for a correlation of crop growth and pest conditions. Results of Model 2 (using the LI indicator) on the other hand, indicate a risk decreasing effect of herbicides and a risk increasing effect of fungicides. Coefficient estimates for the two models (i.e. the two indicators) differ significantly (Table 5). This result confirms expectations derived from the conceptual model, namely that indicator choice influences the estimation of risk effects of pesticides. Furthermore, results indicate that the more risk averse farmers are, the more likely they are to use pesticides in lower quantities but with a higher toxicity, ceteris paribus. We also find different risk effects for herbicides and fungicides (statistically significant in Model 2), in line with results for marginal effects on expected revenues.

We further find that mechanical pest control has a significant positive effect on variance of revenues in Model 1 and a significant negative effect in Model 2. Differences between estimates are highly significant and again point in the same direction as estimates for herbicide use. Fertilizer is found to increase risk significantly in both Models (no significant differences between Models, in line with 
results from marginal effects). This finding is coherent with empirical evidence for Switzerland (Finger, 2012) $)^{23}$.

To summarize our results, we obtain significantly greater estimates of pesticide productivity and risk effects with the (purely quantitative) PQ indicator than with the LI indicator for all damage abating inputs.

\section{Discussion and Conclusion}

The reduction of adverse environmental and health impacts from pesticide use represents a central goal of current agricultural policies. The effects of pesticides on production risks are considered a major driver of pesticide use and should therefore be considered in the design of pesticide policies. Similarly, risk management tools, such as insurance solutions, might be closely linked to pesticide use through its effects on production risks. However, it is not possible to formulate clear policy recommendations since previous studies have provided ambiguous results regarding the risk effects of pesticides, ranging from risk increasing to risk decreasing or even no effect at all. Ambiguous results might be due to the diverse measurements of pesticides used in literature. Based on recent evidence on the heterogeneity of used pesticides (Kniss, 2017; Möhring et al., 2019), this article investigates whether the choice of a pesticide indicator influences the estimation of risk effects of pesticides. We examine the effect of indicator choice on estimation results by means of an econometric analysis of pesticide use on revenues and production risk, using detailed data from Swiss winter wheat producers. In our analysis, we compare an indicator which explicitly accounts for adverse environmental and health impacts of pesticides (LI) (and is consequently of special interest for policy-makers) to a simpler, but often used, quantitative indicator (PQ). Our conceptual and

\footnotetext{
${ }^{23}$ Note however that there is mixed evidence on the risk effects of fertilizer (Babcock, 1992; Isik, 2002; Paulson and Babcok, 2010). In particular, the risk decreasing properties of nitrogen are found in cases when the nutrients available in the soil are unknown; thus applying more nitrogen than necessary can be a risk reducing strategy (i.e. "apply extra fertilizer just in case it is needed", Babcock and Blackmer, 1992). In Switzerland, however, we can assume that farmers are aware of the soil conditions as regular soil testing is a part of cross compliance obligations of farmers.
} 
econometric models explicitly account for the correlation between multiple sources of uncertainty. Results show that pesticide indicator choice has an influence on the estimation of pesticide productivity and risk effects and provide important insights for the design of pesticide policies.

Firstly, we find that uncertainty about crop growth conditions and pest development are highly correlated in Swiss winter wheat production. We further identify pesticides as damage abating inputs in production. Our results thus confirm previous findings in literature, that suggest the use of a production function in the analysis of pesticide use decisions, which accounts for damage abatement and multiple sources of uncertainty. Ignoring these results could lead to biased estimates of pesticide productivity and risks.

Secondly, our results indicate that the risk effects of pesticides differ between pesticide types. When we take the heterogeneous properties (i.e. qualitative and quantitative differences) of pesticides into account, we find significantly different and even opposing estimates of herbicide and fungicide productivity and risk effects. Differences between pesticide types must therefore be given due consideration in efficient pesticide policy design. It follows that pesticide policies which fail to account for this heterogeneity could prove inefficient. For example, pesticide taxes as levied in some European countries (Böcker and Finger, 2016; Finger et al., 2017), should allow for linkages between pesticide use and production risks, i.e. resulting in different marginal risk premiums for different types of pesticides. Policy measures, such as tailored subsidies for a reduced pesticide use, should further consider differences between pest management against weeds, plant diseases or insects.

Thirdly, our results emphasize that indicator choice has an effect on the estimation of pesticide productivity and risk effects. More specifically, we find that the use of a purely quantitative indicator (PQ) systematically leads to greater estimates of herbicide and fungicide productivity and risk effects, compared to an indicator, which considers the heterogeneous properties of the pesticides used (LI). In the case of herbicides, this even lead to sign changes in estimates of productivity and risk effects. Our results indicate that pesticide properties are important criteria for farmers' application decisions. 
The findings suggest that pesticide regulations and compliance criteria aiming to limit application quantities, as well as extension services for farmers based on simple, quantitative measures, might provide ill-advised incentives, which could be avoided by using more sophisticated indicators (e.g. accounting for pesticide quality - Kniss, 2017; Möhring et al., 2019). Since earlier studies used various quantitative indicators and did not account for heterogeneous pesticide properties, the ambiguous results they obtained could be in part due to the influence of indicator choice on the estimation of risk effects. The non-linear dependence structure between quantity and qualitative properties of pesticides (Möhring et al., 2019) appears to be a fundamental reason for the significant influence of indicator choice on estimated risk effects.

An important implication of our results on risk effects of herbicides is that with increasing risk aversion, farmers will ceteris paribus use lower quantities of herbicides (risk increasing effect found with the PQ indicator), but will increase the overall toxicity of the products applied (risk decreasing effect found with the LI indicator). Given our results on risk effects of pesticides, policies (e.g. pesticide taxes), which focus solely on a reduction of used pesticide quantities rather than on the environmental and health impacts of pesticides could in fact have detrimental incentives. Current pesticide policies which focus on the reduction of adverse environmental and health impacts of pesticides, should therefore provide increased support and guidance for farmers' application decisions in risky situations. For example, this could involve the development and improvement of decision support tools or prognosis systems designed to reduce uncertainty with regard to pest development. Policy-makers could also incentivize the development and use of innovative insurance solutions (e.g. Norton et al., 2016), precision farming techniques (e.g. Finger et al., 2019), or new "smart farming" technologies (Walter et al., 2017). Since our results show that herbicides (under the policy relevant indicator definition) are risk reducing, these tools could replace the use of herbicides in risky production decisions. 
The effect of pesticides on production risks is not only relevant for pesticide policies, but also constitutes a direct link to agricultural policy instruments focusing on risk management. Risk management instruments, like income stabilization tools in European agriculture (e.g. El Benni et al., 2016; Severini et al., 2019), or crop insurances (Di Falco et al., 2014) interact with farmers' input decisions, such as pesticide use. The effects of agricultural insurance programs on input use are currently being discussed in the US (Smith and Goodwin, 2013; Weber et al., 2016). Given increasing prospects of insurance in European agriculture (Meuwissen et al., 2018), it is clear that the potential interaction effects on input use are large. Our results show that it depends on the pesticide type and the properties of pesticides if they are substitutes or complements to risk management instruments at the intensive margin. In our case study, herbicides could be complements in terms of quantity but substitutes in terms of toxicity, while fungicides are complements in terms of quantity and toxicity. This finding suggests that restrictions and compliance criteria for risk management tools must be tailored to the specific applications and cultures to which they are applied. A "one fits all" solution could easily lead to unintended incentives for input use, such as an increased use of more toxic pesticides. The link between farmers` individual risk preferences, risk management and pesticide use merits further analysis due to its relevance for current agricultural policies. For example, the effect of agricultural policies on extensive margins (i.e. land use decisions) could be an additional, major driver for pesticide use and is therefore a topic which requires further research.

Finally, our research has some important limitations. We do not account for sequential decision making of farmers, nor do we consider technical efficiency regarding input choices. In future research our framework could be extended in this direction and might well reveal important interactions between application timing and technical efficiency on the one hand and environmental and health effects of pesticides (e.g. self-insurance) on the other hand (see e.g. Antle, 1983; Dionne and Eeckhoudt, 1985; Shee and Stefanou, 2014). Different measures for the farmers' financial risk exposure could be used in future research, e.g. accounting for downside risks and the role of prospect theory for pesticide use decisions (e.g. Liu et al., 2013; Carpentier and Reboud, 2018). Furthermore, 
we do not consider potential long-term implications and dynamics with regard to marginal costs and benefits of pest control, e.g. impacts on the environment (Skevas et al., 2013b) and human health (Liu and Huang, 2013). A more holistic picture of (long-term) pesticide productivity and risk effects could be obtained if these effects were included in future analyses. 


\section{$7 \quad$ References}

AGRIDEA (2009-2013). AGRIDEA Preiskatalog. AGRIDEA, Lindau, Switzerland.

Agroscope (2009). Grundlagen für die Düngung im Acker- und Futterbau GRUDAF 2009.

Forschungsanstalten Agroscope Changins-Wädenswil ACW and Agroscope Reckenholz-Tänikon ART.

Agroscope (2015). Maschinenkosten 2015. Changins, Switzerland: Forschungsanstalten Agroscope Changins-Wädenswil ACW and Agroscope Reckenholz-Tänikon ART, Switzerland.

Antle, J. M. (1983). Sequential decision making in production models. American Journal of Agricultural Economics, 65(2), 282-290.

Antle, J. M. (1988). Pesticide Policy, Production Risk and Producer Welfare: An Econometric Approach to Applied Welfare Economics. Resources for the Future Press, Washington D.C., USA.

Antle, J. M. (2010). Asymmetry, partial moments and production risk. American Journal of Agricultural Economics, 92(5), 1294-1309.

Babcock, B. A. (1992). The effects of uncertainty on optimal nitrogen applications. Review of Agricultural Economics, 14(2), 271-280.

Babcock, B. A. \& Blackmer, A. M. (1992). The value of reducing temporal input nonuniformities. Journal of Agricultural and Resource Economics, 17(2), 335-347.

BFS (2013). Schweizer Landwirtschaft - Taschenstatistik 2013. Bundesamt für Statistik BFS, Neuchâtel, Switzerland.

BFS (2016). Landesindex der Konsumentenpreise. Retrieved from http://www.portal-stat.admin.ch/indivrechner/d/index.html

Bundesamt für Statistik (BFS), GEOSTAT (2017). BFS GEOSTAT Gemeindegrenzen. Retrieved from https:/www.bfs.admin.ch/bfs/de/home/dienstleistungen/geostat/geodaten-bundesstatistik/administrativegrenzen/generalisierte-gemeindegrenzen.html

Billor, N., Hadi, A.S. \& Velleman, P.F. (2000). BACON: blocked adaptive computationally efficient outlier nominators. Computational Statistics \& Data Analysis, 34(3), 279-298.

BLW (2012). BLW Pflanzenschutzmittelverzeichnis. Retrieved from http://www.psm.admin.ch/psm/produkte

Böcker, T. \& Finger, R. (2016). European Pesticide Tax Schemes in Comparison: An Analysis of Experiences and Developments. Sustainability, 8(4), 378.

Böcker, T., Möhring, N. \& Finger, R. (2019). Herbicide free agriculture? A bio-economic modelling application to Swiss wheat production. Agricultural Systems, 173, 378-392.

Bürger, J., de Mol, F. \& Gerowitt, B. (2012). Influence of cropping system factors on pesticide use intensityA multivariate analysis of on-farm data in North East Germany. European Journal of Agronomy, 40, 54-63.

Carpentier, A. \& Weaver, R. D. (1996). Intertemporal and interfirm heterogeneity: implications for pesticide productivity. Canadian Journal of Agricultural Economics/Revue canadienne d'agroeconomie, 44(3), 219236.

Carpentier, A. \& Weaver, R. D. (1997). Damage Control Productivity: Why Econometrics Matters. American Journal of Agricultural Economics, 79(1), 47-61.

Carpentier, A. \& Reboud, X. (2018). Why farmers consider pesticides the ultimate in crop protection: economic and behavioral insights. International Association of Agricultural Economists (IAAE) 2018 Conference, Vancouver, Canada. 
Charles, R., Cholley, E., Frei, P. \& Mascher, F. (2011). Krankheiten beim Winterweizen: Einfluss des Anbausystems und Auswirkungen auf den Ertrag. Agrarforschung Schweiz, 2(6), 264-271.

Cobourn, K. M., Burrack, H. J., Goodhue, R. E., Williams, J. C. \& Zalom, F. G. (2011). Implications of simultaneity in a physical damage function. Journal of Environmental Economics and Management, 62(2), 278-289.

de Baan, L., Spycher, S., \& Daniel, O. (2015). Einsatz von Pflanzenschutzmitteln in der Schweiz von 2009 bis 2012. Agrarforschung Schweiz, 6(2), 48-55.

Di Falco, S. \& Chavas, J. P. (2006). Crop genetic diversity, farm productivity and the management of environmental risk in rainfed agriculture. European Review of Agricultural Economics, 33(3), 289-314.

Di Falco, S., Adinolfi, F., Bozzola, M. \& Capitanio, F. (2014). Crop Insurance as a Strategy for Adapting to Climate Change. Journal of Agricultural Economics, 65(2), 485-504.

Dionne, G., Eeckhoudt, L. (1985). Self-insurance, self-protection and increased risk aversion. Economics Letters, 17(1-2), 39-42.

Dorschner, K. W., Johnson, R. C., Eikenbary, R. D. \& Ryan, J. D. (1986). Insect-plant interactions: greenbugs (Homoptera: Aphididae) disrupt acclimation of winter wheat to drought stress. Environmental entomology, 15(1), 118-121.

El Benni, N., Finger, R. \& Meuwissen, M.P., (2016). Potential effects of the income stabilisation tool (IST) in Swiss agriculture. European Review of Agricultural Economics, 43(3), 475-502.

Farnsworth, R. L. \& Moffitt, L. J. (1981). Cotton production under risk: an analysis of input effects on yield variability and factor demand. Western Journal of Agricultural Economics, 6(2), 155-163.

Feder, G. (1979). Pesticides, information, and pest management under uncertainty. American Journal of Agricultural Economics, 61(1), 97-103.

Finger, R. (2012). Nitrogen use and the effects of nitrogen taxation under consideration of production and price risks. Agricultural Systems, 107, 13-20.

Finger, R., Möhring, N., Dalhaus, T. \& Böcker, T., (2017). Revisiting pesticide taxation schemes. Ecological Economics, 134, 263-266.

Finger, R., Swinton, S. M., Benni, N. E., \& Walter, A. (2019). Precision farming at the nexus of agricultural production and the environment. Annual Review of Resource Economics, 11, 313-335.

Frei, C. (2014). Interpolation of temperature in a mountainous region using nonlinear profiles and nonEuclidean distances. International Journal of Climatology, 34(5), 1585-1605.

Gaba, S., Gabriel, E., Chadœuf, J., Bonneu, F. \& Bretagnolle, V. (2016). Herbicides do not ensure for higher wheat yield, but eliminate rare plant species. Scientific Reports, 6 (30112).

Gardebroek, C., Chavez, M. D. \& Oude Lansink, A. (2010). Analysing production technology and risk in organic and conventional Dutch arable farming using panel data. Journal of Agricultural Economics, 61(1), $60-75$.

Gong, Y., Baylis, K., Kozak, R. \& Bull, G. (2016). Farmers' risk preferences and pesticide use decisions: evidence from field experiments in China. Agricultural Economics, 47, 411-421.

Gotsch, N. \& Regev, U. (1996). Fungicide use under risk in Swiss wheat production. Agricultural Economics, 14, 1-9.

Horowitz, J. K. \& Lichtenberg, E. (1994). Risk-reducing and risk-increasing effects of pesticides. Journal of Agricultural Economics, 45(1), 82-89.

Huber, R., Snell, R., Monin, F., Brunner, S. \& Finger R. (2017). Interaction effects of targeted agrienvironmental payments on non-marketed goods and services under climate change in a mountain region. Land Use Policy, 66, 49-60. 
Hurd, B. H. (1994). Yield response and production risk: An analysis of integrated pest management in cotton. Journal of Agricultural and Resource Economics, 19(2), 313-326.

Isik, M. (2002). Resource management under production and output price uncertainty: implications for environmental policy. American Journal of Agricultural Economics, 84(3), 557-571.

Iyer, P., Bozzola, M., Hirsch, S., Meraner, M., \& Finger, R. (2019). Measuring farmer risk preferences in Europe: a systematic review. Journal of Agricultural Economics, 71(1), 3-26.

Isotta, F. A., Begert, M., \& Frei, C. (2019). Long-Term Consistent Monthly Temperature and Precipitation Grid Data Sets for Switzerland Over the Past 150 Years. Journal of Geophysical Research: Atmospheres, 124(7), 3783-3799.

Kan, I., Motro, Y., Horvitz, N., Kimhi, A., Leshem, Y., Yom-Tov, Y. \& Nathan, R. (2014). Agricultural Rodent Control Using Barn Owls: Is It Profitable? American Journal of Agricultural Economics, 96(3), 733752.

Kniss, A.R., (2017). Long-term trends in the intensity and relative toxicity of herbicide use. Nature communications, 8, 14865.

Koundouri, P. \& Nauges, C. (2005). On production function estimation with selectivity and risk considerations. Journal of Agricultural and Resource Economics, 30(3), 597-608.

Koundouri, P., Laukkanen, M., Myyrä, S. \& Nauges, C. (2009). The effects of EU agricultural policy changes on farmers' risk attitudes. European Review of Agricultural Economics, 36(1), 53-77.

Kudsk, P., Jørgensen, L.N. \& Ørum, J.E. (2018). Pesticide Load-A new Danish pesticide risk indicator with multiple applications. Land Use Policy, 70, 384-393.

Lai, W. (2017). Pesticide Use and Health Outcomes: Evidence from Agricultural Water Pollution in China. Journal of Environmental Economics and Management, 86, 93-120.

Larsen, A. E., Gaines, S. D. \& Deschênes, O. (2017). Agricultural pesticide use and adverse birth outcomes in the San Joaquin Valley of California. Nature Communications, 8(1), 302.

Lefebvre, M., Langrell, S. R. \& Gomez-y-Paloma, S. (2015). Incentives and policies for integrated pest management in Europe: a review. Agronomy for Sustainable Development, 35(1), 27-45.

Levinsohn, J. \& Petrin, A. (2003). Estimating production functions using inputs to control for unobservables. The Review of Economic Studies, 70(2), 317-341.

Lewis, K. A., Tzilivakis, J., Warner, D. J. \& Green, A. (2016). An international database for pesticide risk assessments and management. Human and Ecological Risk Assessment: An International Journal, 22(4), 1050-1064.

Liu, E. M. \& Huang, J. (2013). Risk preferences and pesticide use by cotton farmers in China. Journal of Development Economics, 103, 202-215.

Lichtenberg, E. \& Zilberman, D. (1986). The econometrics of damage control: why specification matters. American Journal of Agricultural Economics, 68(2), 261-273.

Maxmen, A. (2013). Crop Pests: Under attack. Nature, 501(7468), S15.

Meuwissen, M. P., Mey, Y. D. \& van Asseldonk, M. (2018). Prospects for agricultural insurance in Europe. Agricultural Finance Review, 78(2), 174-182.

Miljøministeriet (2012). The Agricultural Pesticide Load in Denmark 2007-2010. Environmental review no. 2, Miljøstyrelsen, Kopenhagen, Denmark.

Möhring, N., Gaba, S. \& Finger, R., (2019). Quantity based indicators fail to identify extreme pesticide risks. Science of The Total Environment, 646, 503-523. 
Mouron, P. \& Schmid, D. (2012). Grundlagenbericht 2011: Zentrale Auswertung von Buchhaltungsdaten. Agroscope INH, Ettenhausen, Switzerland.

Norton, M., van Sprundel, G. J., Turvey, C. G. \& Meuwissen, M. P. (2016). Applying weather index insurance to agricultural pest and disease risks. International Journal of Pest Management, 62(3), 195-204.

Olley, G. S. \& Pakes, A. (1996). The dynamics of productivity in the telecommunications equipment industry. Econometrica, 64(6), 1263-1297.

Osteen, C.D. \& Fernandez-Cornejo, J., (2013). Economic and policy issues of US agricultural pesticide use trends. Pest management science, 69(9), 1001-1025.

Pannell, D. J. (1991). Pests and pesticides, risk and risk aversion. Agricultural Economics, 5(4), 361-383.

Paternoster, R., Brame, R., Mazerolle, P. \& Piquero, A., (1998). Using the correct statistical test for the equality of regression coefficients. Criminology, 36(4), 859-866.

Paulson, N. D. \& Babcock, B. A. (2010). Readdressing the fertilizer problem. Journal of Agricultural and Resource Economics, 35(3), 368-384.

Perry, E.D., Ciliberto, F., Hennessy, D.A. \& Moschini, G., (2016). Genetically engineered crops and pesticide use in US maize and soybeans. Science advances, 2(8), e1600850.

Perry, E. D., Hennessy, D. A. \& Moschini, G., (2019). Product concentration and usage: Behavioral effects in the glyphosate market. Journal of Economic Behavior \& Organization, 158, 543-559.

Pimentel, D. \& Burgess, M. (2014). Environmental and economic costs of the application of pesticides primarily in the United States. In Integrated Pest Management. Dordrecht, Netherlands: Springer.

Praneetvatakul, S., Schreinemachers, P. \& Laitae, C. (2016). Pesticide Risk Behavior and Knowledge of Chili and Tomato Farmers. International Journal of Vegetable Science, 22(4), 1-13.

Regev, U., Gotsch, N. \& Rieder, P. (1997). Are fungicides, nitrogen and plant growth regulators riskreducing? Empirical evidence from Swiss wheat production. Journal of Agricultural Economics, 48(1-3), $167-178$.

Saha, A., Shumway, C. R. \& Havenner, A. (1997). The economics and econometrics of damage control. American Journal of Agricultural Economics, 79(3), 773-785.

Serra, T., Zilberman, D., Goodwin, B. K. \& Featherstone, A. (2006). Effects of Decoupling on the Mean and Variability of Output. European Review of Agricultural Economics, 33, 269-288.

Serra, T., Zilberman, D. \& Gil, J. M. (2008). Farms' technical inefficiencies in the presence of government programs. Australian Journal of Agricultural and Resource Economics, 52(1), 57-76.

Severini, S., Biagini, L. \& Finger, R. (2019). Modeling agricultural risk management policies-The implementation of the Income Stabilization Tool in Italy. Journal of Policy Modeling, 41(1), 140-155.

Shankar, B., Bennett, R. \& Morse, S. (2008). Production risk, pesticide use and GM crop technology in South Africa. Applied Economics, 40(19), 2489-2500.

Shee, A. \& Stefanou, S. E. (2014). Endogeneity corrected stochastic production frontier and technical efficiency. American Journal of Agricultural Economics, 97(3), 939-952.

Skevas, T., Lansink, A. O. \& Stefanou, S. E. (2013a). Designing the emerging EU pesticide policy: A literature review. NJAS-Wageningen Journal of Life Sciences, 64, 95-103.

Skevas, T., Stefanou, S. E. \& Lansink, O. A. (2013b). Do farmers internalise environmental spillovers of pesticides in production? . Journal of Agricultural Economics, 64(3), 624-640.

Skevas, T., Stefanou, S. E. \& Lansink, O. A. (2014). Pesticide use, environmental spillovers and efficiency: A DEA risk-adjusted efficiency approach applied to Dutch arable farming. European Journal of Operational Research, 237, 658-664. 
Smith, V.H. \& Goodwin, B.K., (2013). The environmental consequences of subsidized risk management and disaster assistance programs. Annual Review of Resource Economics, 5(1), 35-60.

Spycher, S., Badertscher, R. \& Daniel, O. (2013). Indikatoren für den Einsatz von Pflanzenschutzmitteln in der Schweiz. Agrarforschung Schweiz, 4(4), 192-199.

Swinton, S. M. \& Van Deynze, B. (2017). Hoes to Herbicides: Economics of Evolving Weed Management in the United States. The European Journal of Development Research, 29(3), 560-574.

Teixeira, M.C., Duque, P. \& Sá-Correia, I. (2007). Environmental genomics: mechanistic insights into toxicity of and resistance to the herbicide 2, 4-D. Trends in biotechnology, 25(8), 363-370.

Trujillo-Barrera, A., Joost M. E. Pennings \& Hofenk, D. (2016). Understanding producers' motives for adopting sustainable practices: the role of expected rewards, risk perception and risk tolerance. European Review Agricultural Economics, 43(3), 359-382.

Walter, A., Grieder, C., Last, L., Keller, B., Hund, A. \& Studer, B. (2014). Die Schweizer Pflanzenzüchtung-eine räumliche, zeitliche und thematische Analyse des Umfeldes. Agrarforschung Schweiz, 5(9), 366-373.

Walter, A., Finger, R., Huber, R. \& Buchmann, N. (2017). Opinion: Smart farming is key to developing sustainable agriculture. Proceedings of the National Academy of Sciences, 114(24), 6148-6150.

Weber, J.G., Key, N. \& O’Donoghue, E. (2016). Does Federal Crop Insurance Make Environmental Externalities from Agriculture Worse?. Journal of the Association of Environmental and Resource Economists, 3(3), 707-742.

Yuan, J.S., Tranel, P.J. \& Stewart, C.N. (2007). Non-target-site herbicide resistance: a family business. Trends in plant science, 12(1), 6-13.

Zhengfei, G., Lansink, A. O., Wossink, A. \& Huirne, R. (2005). Damage control inputs: a comparison of conventional and organic farming systems. European Review of Agricultural Economics, 32(2), 167-189.

Zhengfei, G., Lansink, A. O., van Ittersum, M. \& Wossink, A. (2006). Integrating agronomic principles into production function specification: a dichotomy of growth inputs and facilitating inputs. American Journal of Agricultural Economics, 88(1), 203-214. 


\section{Tables}

Table 1. Summary statistics of variables

\begin{tabular}{|c|c|c|c|c|c|}
\hline Variable & Mean & SD & Min. & Max. & Definition \\
\hline $\begin{array}{l}\text { Planted area } \\
\text { winter wheat }\end{array}$ & 5.65 & 4.28 & 0.28 & 23.26 & Planted area of winter wheat in ha. \\
\hline $\begin{array}{l}\text { Share winter } \\
\text { wheat }\end{array}$ & 0.20 & 0.11 & 0.02 & 0.57 & $\begin{array}{l}\text { Share of agricultural land under winter } \\
\text { wheat. }\end{array}$ \\
\hline Zone & 0.23 & 0.42 & 0 & 1 & $\begin{array}{l}\text { Binary variable. Indicates if the farm is } \\
\text { located in a mountainous zone. }\end{array}$ \\
\hline Region & 0.40 & 0.49 & 0 & 1 & $\begin{array}{l}\text { Binary variable. Indicates if the farm is } \\
\text { located in the French speaking (western) } \\
\text { part of Switzerland. }\end{array}$ \\
\hline Revenues & 2973 & 622 & 814 & 4901 & Revenue for winter wheat in CHF per ha. \\
\hline $\begin{array}{l}\text { Work and } \\
\text { machinery }\end{array}$ & 1451 & 297 & 469 & 2272 & $\begin{array}{l}\text { Work and machinery costs in CHF per } \\
\text { ha. }\end{array}$ \\
\hline Fertilizer & 154 & 49 & 11 & 342 & Fertilizer in kg of nitrogen per ha. \\
\hline $\begin{array}{l}\text { Mechanical pest } \\
\text { control }\end{array}$ & 288 & 198 & 0 & 900 & $\begin{array}{l}\text { Work and machinery costs for } \\
\text { mechanical pest control in CHF per ha. }\end{array}$ \\
\hline Herbicides (PQ) & 1.59 & 1.86 & 0 & 11.03 & Herbicide use in kg per ha. \\
\hline Fungicides (PQ) & 1.27 & 1.33 & 0 & 10.33 & Fungicide use in kg per ha. \\
\hline Herbicides (LI) & 0.89 & 1.28 & 0 & 28.75 & Herbicide use in Load Index units per ha. \\
\hline Fungicides (LI) & 1.42 & 1.28 & 0 & & Fungicide use in Load Index units per ha \\
\hline
\end{tabular}

Note: summary statistics are computed for the pooled dataset from 2009-2013 with $\mathrm{N}=268$. 
Table 2. Comparison of sample and population averages

\begin{tabular}{lccl} 
Variable & $\begin{array}{c}\text { Sample } \\
\text { average }\end{array}$ & $\begin{array}{c}\text { Population } \\
\text { average }\end{array}$ & Description (source population average) \\
\hline Total farm size (ha) & 27.5 & 26.3 & $\begin{array}{l}\text { Total arable land of crop farmers in hectares } \\
\text { (Mouron and Schmid, 2012). }\end{array}$ \\
$\begin{array}{l}\text { Planted area winter } \\
\text { wheat (ha) }\end{array}$ & 5.65 & 6.3 & $\begin{array}{l}\text { Total area under winter wheat (145176 ha) } \\
\text { divided by number of farms growing winter } \\
\text { wheat in Switzerland (23000; BFS, 2013). }\end{array}$ \\
\hline Age (in categories) & & & Age of main farm operator (BFS, 2013). \\
\hline$<39$ years & $24 \%$ & $17 \%$ & \\
\hline $\mathbf{4 0 - 4 9}$ years & $30 \%$ & $32 \%$ & \\
\hline $\mathbf{5 0 - 5 9}$ years & $36 \%$ & $33 \%$ & \\
$>\mathbf{6 0}$ years & $10 \%$ & $18 \%$ & \\
\hline
\end{tabular}

Note, that we selected those studies, which report population averages of Swiss farmers closest to 2011, i.e. the middle of our sample years. Data comes from Agroscope for the year 2011 (Mouron and Schmid, 2012) and the Swiss Institute for Statistics (BFS) for the year 2011 (BFS, 2013). Sample averages are computed for the pooled dataset from 2009-2013 with $\mathrm{N}=268$. 
Table 3. Test results of separability and asymmetry tests

\begin{tabular}{l|lllc}
\hline \hline & $\begin{array}{l}\text { Testing framework } \\
\text { (see Eq. 4) }\end{array}$ & $\begin{array}{l}\text { Null-hypothesis } \\
\text { for coefficients }\end{array}$ & \multicolumn{2}{c}{$\boldsymbol{p}$-Value per model } \\
\hline Separability tests & $\begin{array}{l}\text { Production function } h(.) \\
\text { (trans-log specification) } \\
\text { Production function } h(.) \\
\text { (quadratic specification) } \\
\text { Output function } \\
h(.) *(1-d(.))\end{array}$ & $\boldsymbol{x} \mathbf{z}=0$ & 0.72 & 0.36 \\
\hline Asymmetry tests & $\begin{array}{l}\text { Output function } \\
h(.) *(1-d(.))\end{array}$ & $\boldsymbol{x}_{\mathbf{z}=0}$ & 0.54 & 0.86 \\
\hline \hline
\end{tabular}

Note: PQ and LI indicate that pesticide use is expressed with the Pesticide Quantity and Load Index indicators in the respective models. P-values are indicated for Wald tests on the hypothesis that the coefficients of the indicated variables are jointly zero in the respective estimations. Sample size is $N=268$. 
Table 4. Marginal effects of damage abating and interactive inputs on expected revenues and variance

\begin{tabular}{lcccc}
\hline \hline & \multicolumn{2}{c}{ Model 1 (PQ) } & \multicolumn{2}{c}{ Model 2 (LI) } \\
& Estimate & z-value & Estimate & z-value \\
\hline Marginal effects on expected revenues & & & \\
\hline Herbicides & $15.42^{* *}$ & 2.11 & $-2.07^{* * *}$ & -2.63 \\
Fungicides & $29.33^{* *}$ & 2.18 & $4.07 * *$ & 2.44 \\
Mechanical pest control & $0.09^{* *}$ & 1.96 & $-0.32^{* * *}$ & -2.82 \\
Fertilizer & $6.71^{* *}$ & 2.35 & $11.34 * * *$ & 2.92 \\
& & & & \\
Marginal effects on the variance & & & & -2.63 \\
\hline Herbicides & & & $-0.25 * * *$ & 2.44 \\
Fungicides & $5.09^{* *}$ & 2.20 & $0.49^{* * *}$ & -2.82 \\
Mechanical pest control & $9.68^{* *}$ & 2.27 & $-0.04 * * *$ \\
Fertilizer & $0.03^{* *}$ & 2.05 & $0.51^{* * *}$ & 2.92 \\
& $0.86^{* * *}$ & 2.47 & & \\
\hline \hline
\end{tabular}

Note: Marginal effects are calculated at mean values of all variables. Marginal effects on expected revenues and on variance are expressed in CHF and percentage of overall model variance, respectively. PQ and LI stand for Pesticide Quantity and Load Index indicator, expressing pesticide use in $\mathrm{kg} / \mathrm{ha}$ and Load Index units/ha, respectively. Standard errors are calculated with the delta method, and are based on farm-level cluster adjusted model estimates. $* * *$, and $* * *$ indicate significance at $10 \%, 5 \%$ and $1 \%$ levels, respectively. The sample size is $\mathrm{N}=268$. 
Table 5. Tests of differences between models and pesticide types

\begin{tabular}{|c|c|c|c|}
\hline \multirow[b]{2}{*}{ Marginal effects on expected revenues } & \multirow[t]{2}{*}{$\begin{array}{l}\text { Differences Model } 1 \\
\text { (PQ) and Model } 2 \text { (LI) }\end{array}$} & \multicolumn{2}{|c|}{$\begin{array}{c}\text { Differences pesticide } \\
\text { types }\end{array}$} \\
\hline & & $\begin{array}{l}\text { Model } 1 \\
\quad(P Q)\end{array}$ & $\begin{array}{l}\text { Model } 2 \\
\text { (LI) }\end{array}$ \\
\hline Herbicides & $-2.37 * *$ & \multirow{2}{*}{-0.91} & \multirow{2}{*}{$-3.33 * * *$} \\
\hline Fungicides & $-1.86^{*}$ & & \\
\hline Mechanical pest control & $-3.35 * * *$ & & \\
\hline Fertilizer & 0.96 & & \\
\hline
\end{tabular}

Marginal effects on the variance

\begin{tabular}{lccc}
\hline Herbicides & $-2.47^{* * *}$ & -0.95 & $-3.42 * * *$ \\
Fungicides & $-1.95 * *$ & & \\
Mechanical pest control & $-3.48^{* * *}$ & & \\
Fertilizer & 0.83 &
\end{tabular}

Note: PQ and LI stand for Pesticide Quantity and Load Index indicator, expressing pesticide use in $\mathrm{kg} / \mathrm{ha}$ and Load Index units/ha, respectively. Values denote z-values of z-tests for differences in estimates between the two models and two pesticide types, respectively (Paternoster et al. 1998). ${ }^{* * *}$, and *** indicate significance at $10 \%, 5 \%$ and $1 \%$ levels respectively. The sample size is $\mathrm{N}=268$. 


\section{Figures}

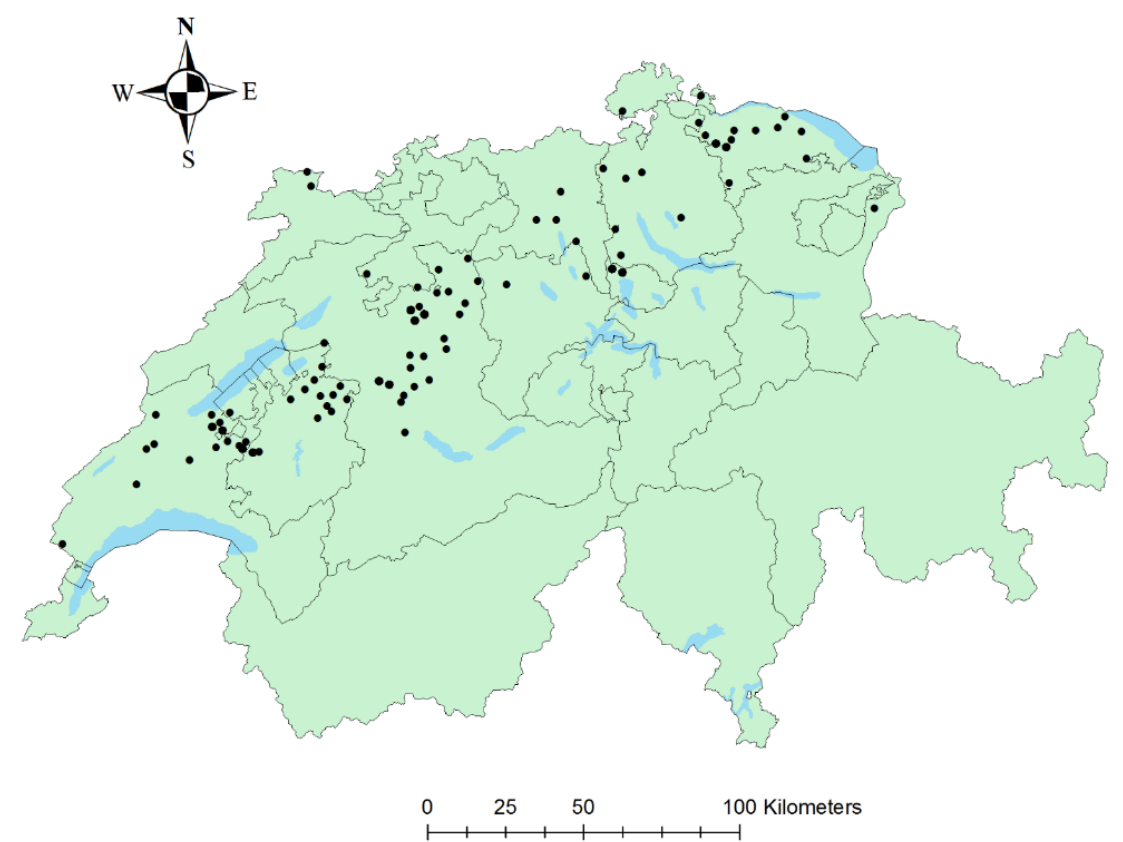

Figure 1. Location of sample farms in Switzerland

Source: Own illustration, shapefiles from Bundesamt für Statistik (BFS), GEOSTAT (2017). Dots indicate the location of the municipalities of sample farms. 